\title{
THE PREVALENCE OF CATARACT IN TWO VILLAGES OF NORTHERN PAKISTAN WITH DIFFERENT LEVELS OF ULTRAVIOLET RADIATION
}

\author{
MATTHEW BURTON ${ }^{1}$, EMMA FERGUSSON ${ }^{2}$, ALISTER HART $^{1}$, KATHRYN KNIGHT ${ }^{1}$, \\ DAVID LARY ${ }^{3}$ and CHRISTOPHER LIU ${ }^{4}$ \\ Cambridge
}

\begin{abstract}
SUMMARY
To study the effect of ultraviolet (UV) light on the development of age-related cataract, a communitybased cross-sectional study was undertaken in two villages in the mountainous Northern Areas of Pakistan. The relative UV light exposure was calculated by the UK Universities Global Atmospheric Modelling Program using the variables direct sunlight hours per day, latitude and ground reflectivity. A total of 797 subjects ( 410 men, 387 women) over the age of 40 years from both villages were examined for the presence of cataract. The prevalence of cataract increased with age $(p<0.001)$ and was significantly higher in women at all ages $(p<0.01)$. There was no significant difference in the overall prevalence of cataract between the two villages. The male population in each village was subdivided into those who worked predominantly indoors and those who worked predominantly outdoors. All women worked outdoors. There was no significant difference in the prevalence of cataract between the male outdoor workers in the two villages. The indoor workers in the village with higher UV light exposure (Hunza) had a significantly higher cataract prevalence $(p<0.001)$ than the indoor workers in the village with lower UV light exposure (Nomol). In the village with lower UV light exposure (Nomol), the male outdoor workers had a significantly higher prevalence of cataract than the male indoor workers $(p<0.001)$. There was no significant difference in the prevalence of cataract between the male indoor and outdoor workers in the village with higher UV light exposure (Hunza). Overall, these results are not strongly supportive of $\mathrm{UV}$ light being
\end{abstract}

From: ${ }^{1}$ Gonville and Caius College, Cambridge; ${ }^{2}$ Selwyn College, Cambridge; ${ }^{3}$ Centre for Atmospheric Sciences, Department of Chemistry, Cambridge University; ${ }^{4}$ Department of Ophthalmology, Addenbrooke's Hospital, Cambridge, UK.

Correspondence to: Dr M. J. Burton, Nuffield Department of Medicine, The John Radcliffe Hospital, Oxford OX3 9DU, UK. of major importance in cataractogenesis, but they are consistent with a saturation model of $U V$ light as a risk factor for cataract formation.

Cataract is an important disease which accounts for the loss of vision in more than half of the world's 23 million blind people. ${ }^{1}$ Senile cataract seems to have a multifactorial aetiology and it has proved difficult to evaluate the contribution of its various components. ${ }^{2}$

A high prevalence of cataract has been shown in tropical countries when compared with developed countries. ${ }^{3}$ These areas have high ultraviolet (UV) light levels and so it was thought that this may be at least partly responsible for the increased prevalence of cataract. These areas, however, also have a high incidence of malnutrition and dehydration, the latter of which is thought to be important in cataractogenesis. ${ }^{4}$ In addition, previous studies often did not control for genetic and cultural differences between the groups studied. ${ }^{5.6}$

In this study we investigated the possible relationship between cataract development and UV light exposure whilst controlling for all other known risk factors. This was made possible by studying two neighbouring communities which are very similar in all respects except that they are in areas with different exposures to UV light.

\section{Subjects}

\section{METHOD}

The target populations were all persons aged 40 years and over living in two isolated villages situated in the mountainous Northern Areas of Pakistan: Hunza and Nomol. The lifestyles and genetic makeup of these two villages are very similar. Both villages have fresh glacial water supplies, grow similar crops using traditional methods, and are 
predominantly Ishmali Muslims. The standard of living was similar in the two villages although this was not formally quantitated. Two generations ago a large number of complete families (rather than just healthy individuals) migrated en masse from Hunza to Nomol because of the pressure of space (personal communication: Mir of Hunza) and therefore the two populations are genetically very similar.

The total UV light exposure of the two populations, however, is different as a result of two factors. Firstly, snow, which reflects more incident UV light $(70 \%)$ than normal ground $(35 \%),{ }^{7}$ is present in Hunza for at least 3 months of the year whereas Nomol very rarely receives snow. Secondly, there is a considerable difference in the topography around the two villages.

There was also some difference in the UV light exposure of individuals from the same village as a result of occupation. The male population in each village was subdivided into those who worked predominantly indoors (for example shopkeepers, teachers, office workers) and those who worked predominantly outdoors (for example farmers/ labourers). This division applied only to the men as all the women worked mostly outdoors.

There are no formal census data for this area. To achieve the highest possible response rate a mobile medical unit was initially set up in the centre of each village. Announcements were made from the loudspeakers of the local mosques. All visitors were examined and given basic ophthalmic treatment (eye ointments and vitamins) by a Pakistani ophthalmologist. Only those of 40 years and over living in the target villages were entered into the study. (People from other villages were examined and treated but were excluded from our study.) After several days the flow of new people to the central unit dropped off. At this point we went around the whole of both study villages visiting each household in turn to examine any person who had not come to the central unit. Households were revisited if any member was not initially available.

\section{Subject Interview and Examination}

Each subject was interviewed using a standard questionnaire consisting of questions about name, age, sex, area within the village where they lived,

Table I. Cataract grading system (after Mehra and Minassian ${ }^{8}$ )

\begin{tabular}{|c|c|}
\hline Grade & Criteria \\
\hline 0 & Clear red reflex, no opacities \\
\hline 1 & Few small dot opacities, maximum area occupied $<1 \mathrm{~mm}^{2}$ \\
\hline $2 \mathrm{~A}$ & $\begin{array}{l}\text { Lens opacity obscuring part of red reflex. Area obscured } \\
\text { is smaller than area of clear reflex }\end{array}$ \\
\hline $2 \mathrm{~B}$ & $\begin{array}{l}\text { As } 2 \mathrm{~A} \text {, but area obscured is equal to or greater than } \\
\text { area of clear red reflex }\end{array}$ \\
\hline 3 & Lens opacity totally obscuring the red reflex \\
\hline 4 & Aphakia or displaced lens \\
\hline 5 & Unable to assess red reflex owing to corneal opacities \\
\hline
\end{tabular}

occupational history, migration history, use of spectacles, ocular trauma and main source of water. Height and weight were measured to calculate the body mass index (BMI). Visual acuity was assessed using a Tumbling $\mathrm{E}$ chart. The subjects were then examined inside a dark mobile medical unit using a standardised ocular examination. The large number of subjects in our field study necessitated the use of a simple, rapid and reliable grading of central lens opacities, as per Mehra and Minassian. ${ }^{8}$ Pupils were not dilated. The red reflex was examined and any opacities were graded (Table I). If cataract was present it was subclassified using a slit lamp. Where possible each patient was examined by two members of the team (M.B., E.F., A.H., K.K.). Urine was tested for the presence of sugar using Diastix to identify diabetes mellitus.

In the analysis of the results, a person was classified as having a cataract when opacities of category $2 \mathrm{~A}$ or greater were present according to the Mehra-Minassian grading system, and where the visual acuity was also reduced to $6 / 18$ or worse, in the same eye. Subjects with diabetes, a history of ocular injury and corneal pathology were excluded from the analysis. The results were analysed using SPSS/PC+.

\section{Estimation of $U V$ Light Exposure}

To quantify the difference in the level of UV radiation between the two valleys several radiation calculations were performed by the UK Universities Global Atmospheric Modelling Program at the Department of Chemistry, Cambridge University.

The cornea absorbs virtually all light of wavelengths shorter than $300 \mathrm{~nm}$. The atmosphere strongly absorbs light with wavelengths shorter than $310 \mathrm{~nm}$, whereas it is optically thin for that longer than $310 \mathrm{~nm}$. Altitude has little effect on the number of photons reaching the lens. Therefore the wavelengths that are most likely to be important for causing cataracts are those in the region 310-500 nm. When considering the number of photons reaching the lens in this spectral region the most important variables are the ground reflectivity and the position of the sun.

Most of the UV radiation that reaches the eye is scattered, rather than direct from the sun. Therefore ground reflectivity is a very important variable. The highest reflectivity or albedo is for areas covered with snow and ice and is typically around 0.7 (i.e. $70 \%$ of the photons are reflected). The global average albedo for areas not covered by snow is 0.35 . The position of the sun is usually expressed by the solar zenith angle, namely the angle between a direct beam from the sun and a normal to the earth's surface.

The skyline for each valley was plotted and then the average maximum zenith angle was estimated for 
Table II. Age, body mass index (BMI) and cataract prevalence for both sexes in Hunza and Nomol

\begin{tabular}{lll}
\hline Men & $\begin{array}{l}\text { Hunza }(n=204) \\
\text { Mean }(\mathrm{SD})\end{array}$ & $\begin{array}{l}\text { Nomol }(n=206) \\
\text { Mean }(\mathrm{SD})\end{array}$ \\
\hline Age (years) & $59.0(12.6)$ & $57.0(12.4)$ \\
BMI $\left(\mathrm{kg} / \mathrm{m}^{2}\right)$ & $22.3(2.9)$ & $22.0(2.5)$ \\
Cataract prevalence & $42.0 \%(n=87)$ & $30.6 \%(n=63)$ \\
\hline Women & Hunza $(n=195)$ & Nomol $(n=192)$ \\
\hline Age $($ years $)$ & $54.4(10.8)$ & $51.9(10.2)$ \\
BMI $\left(\mathrm{kg} / \mathrm{m}^{2}\right)$ & $22.2(3.5)$ & $22.4(3.6)$ \\
Cataract prevalence & $37.4 \%(n=73)$ & $34.4 \%(n=66)$ \\
\hline Men and women & Hunza $(n=399)$ & Nomol $(n=398)$ \\
\hline Cataract prevalence & $40.1 \%(n=160)$ & $32.4 \%(n=129)$ \\
\hline
\end{tabular}

which the valley floor could receive direct sunlight. The number of photons reaching a person in Hunza relative to Nomol in any day was calculated by sampling the sun's position 1000 times for that day and then summing the number of photons at the earth's surface weighted by the albedo and measured absorbance of a crystalline lens for a 45-year-old person.

\section{Subjects}

\section{RESULTS}

A total of 797 subjects were studied in the two villages. There is no official census data but this figure, we believe, represents an extremely high response rate. We knew of fewer than 10 persons who declined to take part. The two communities had similar age and sex structures and no significant difference in BMI (both were within the normal range of 20-26), cataract prevalence (Table II) or percentage of indoor workers. Both villages have fresh glacial water supplies with no habitations upstream. Levels of sanitation are the same. Thus it would be reasonable to infer that the rate of severe
Table III. Age and body mass index (BMI) for male outdoor and indoor workers in Hunza and Nomol

\begin{tabular}{|c|c|c|c|c|}
\hline & \multicolumn{2}{|c|}{ Hunza } & \multicolumn{2}{|c|}{ Nomol } \\
\hline & $\begin{array}{l}\text { Outdoor } \\
(n=136)\end{array}$ & $\begin{array}{l}\text { Indoor } \\
(n=68)\end{array}$ & $\begin{array}{l}\text { Outdoor } \\
(n=144)\end{array}$ & $\begin{array}{l}\text { Indoor } \\
(n=62)\end{array}$ \\
\hline Age (years) & $61.4(12.9)$ & $54.2(10.5)$ & $60.0(12.8)$ & $50.2(8.1)$ \\
\hline BMI $\left(\mathrm{kg} / \mathrm{m}^{2}\right)$ & $22.2(3.0)$ & $22.4 \quad(2.7)$ & $22.0 \quad(2.6)$ & $22.2(2.5)$ \\
\hline
\end{tabular}

Values are the mean (SD).

dehydration crisis would also be the same. There was no significant difference in BMI between the male indoor and outdoor workers of the two villages (Table III) and the observed diets were the same, thus suggesting that both communities had a similar nutritional status. However, the age structures of the male indoor workers and the male outdoor workers were slightly different, with indoor workers tending to be younger in both villages (Table III). There was also a difference in income between indoor and outdoor workers, again in both villages.

\section{Cataract Prevalence}

A trend of increasing cataract prevalence with age was seen in both men and women $(p<0.001)$. At all ages women had a significantly higher cataract prevalence than men $(p<0.01$, Mantel Haenszel age-adjusted chi-squared test) (Fig. 1).

There was no significant difference in overall cataract prevalence between either the men or the women of the two villages. However, when the male subjects were compared by occupational exposure, the following observations were made. Firstly, there was no significant difference between the male outdoor workers of the two villages (Fig. 2). Secondly, the indoor workers in the village with higher UV light exposure (Hunza) had a significantly higher cataract prevalence than the indoor workers in the village with lower UV light exposure (Nomol) (Fig. 2; Mantel Haenszel test: chi-squared $=18.6$,

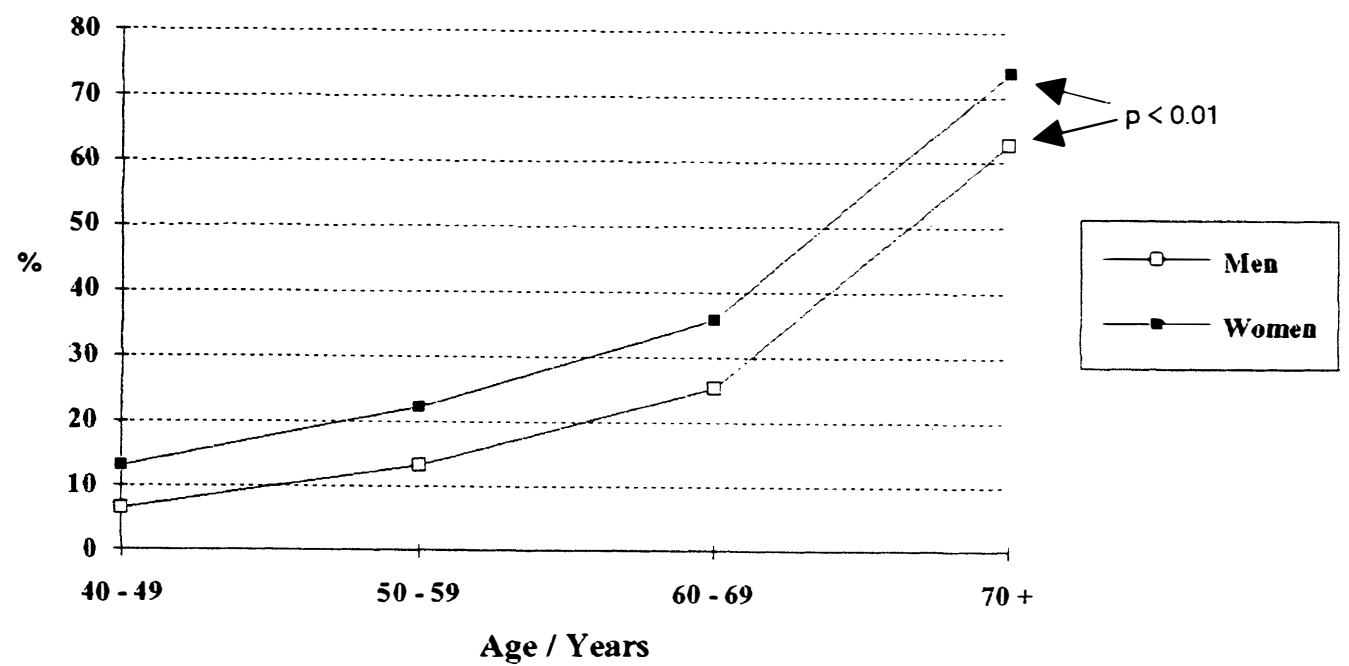

Fig. 1. Age-specific cataract prevalence in men and women from Hunza and Nomol. 


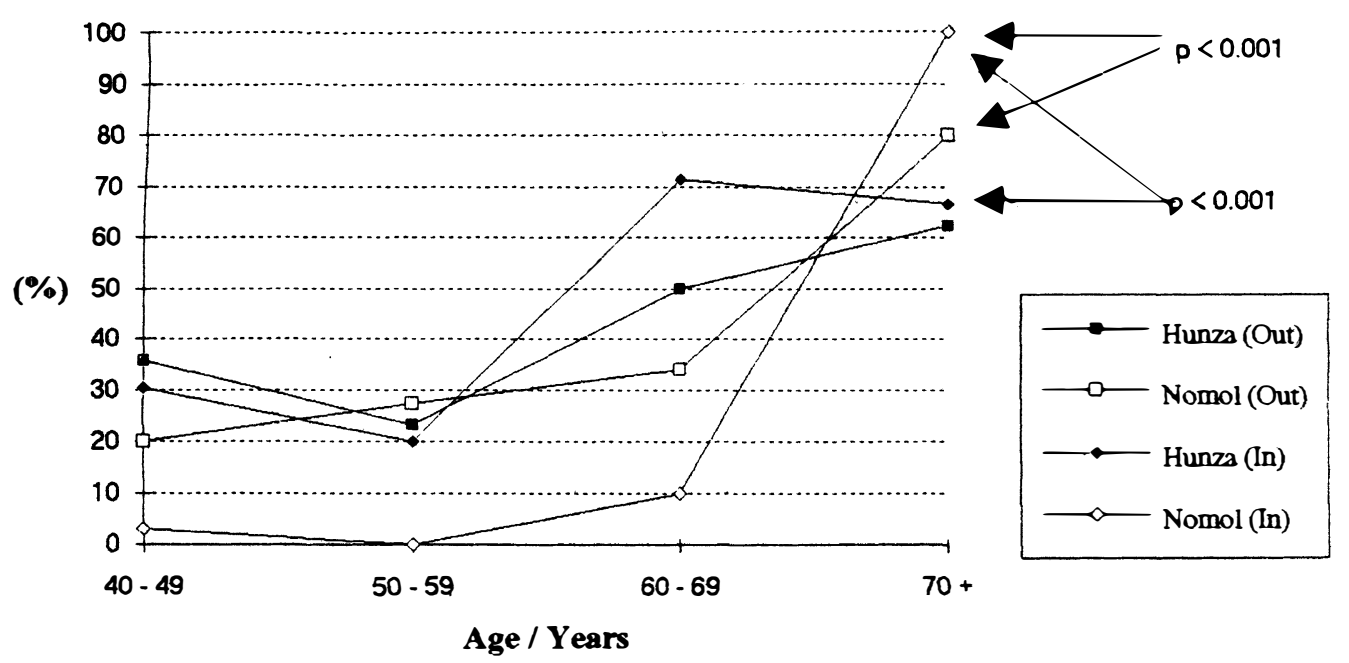

Fig. 2. Age-specific cataract prevalence for male indoor and outdoor workers from Hunza and Nomol.

$p<0.001$ ). Thirdly, in Nomol (lower UV) the male outdoor workers had a significantly higher prevalence of cataract than the male indoor workers $(p<0.001)$. Finally, in Hunza (higher UV) there was no significant difference in the prevalence of cataract between male indoor and outdoor workers.

Analysis of cataract prevalence by type was not performed because the numbers involved were too small. A total of 270 subjects who had lens opacities were tested for diabetes mellitus and only 1 of these was found to be diabetic.

\section{UV Light Exposure}

Nomol, the lower village $(1640 \mathrm{~m}, 5000$ feet $)$, does not usually receive any snow throughout the year, whereas Hunza, the higher village $(2625 \mathrm{~m}, 8000$ feet), has snow cover for at least 3 months of the

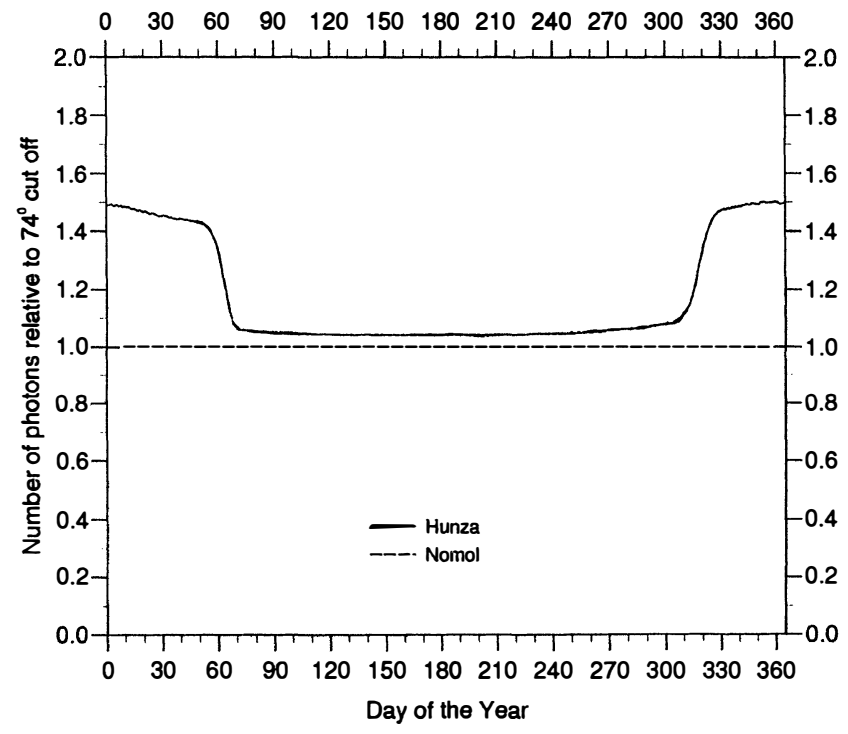

Fig. 3. Number of photons reaching a person's lens in Hunza relative to Nomol (1.0) (wavelength between $300 \mathrm{~nm}$ and $600 \mathrm{~nm}$, weighted by the absorbance of a crystalline lens for a 45-year-old person). year. As a result the inhabitants of Nomol are exposed to $30 \%$ less UV light than those of Hunza during these months of the year. Furthermore, Nomol is situated in a deep, steep-sided valley with a maximum zenith angle of $74^{\circ}$. This contrasts with Hunza which is in a much wider, more open valley with a maximum zenith angle of $82^{\circ}$. As a result of the increased shading effect in Nomol the inhabitants there are exposed to less direct sunlight each day for the whole year - an additional factor of $14 \%$ less UV light than those of Hunza. Fig. 3 illustrates the relative additional UV radiation received in Hunza relative to Nomol throughout the year. A relief map of the area where the expedition took place is shown in Fig. 4.

Hats are worn by a proportion of men and women in both villages, but in each case the type of hat worn does not have a brim and therefore does not offer any protection against direct sunlight entering the eye. Sunglasses were not available in this region, and none were worn by the people we studied.

\section{DISCUSSION}

This study set out to evaluate the role of UV light in cataractogenesis. The approach taken was to compare two populations similar in all respects except for their exposure to UV light.

The two populations studied are highly comparable. Firstly, they are genetically very similar due to the recent migration of people from Hunza to Nomol. This was a mass migration of whole families, thus ruling out any healthy worker/migrant effect. Secondly, their demographic, biological (including BMI) and socio-economic characteristics are similar. We can therefore assume that other aetiological factors in cataractogenesis may be regarded as equal. However, there is a significant difference in the exposure to UV light between the two villages (39\% in winter and $14 \%$ in summer). 


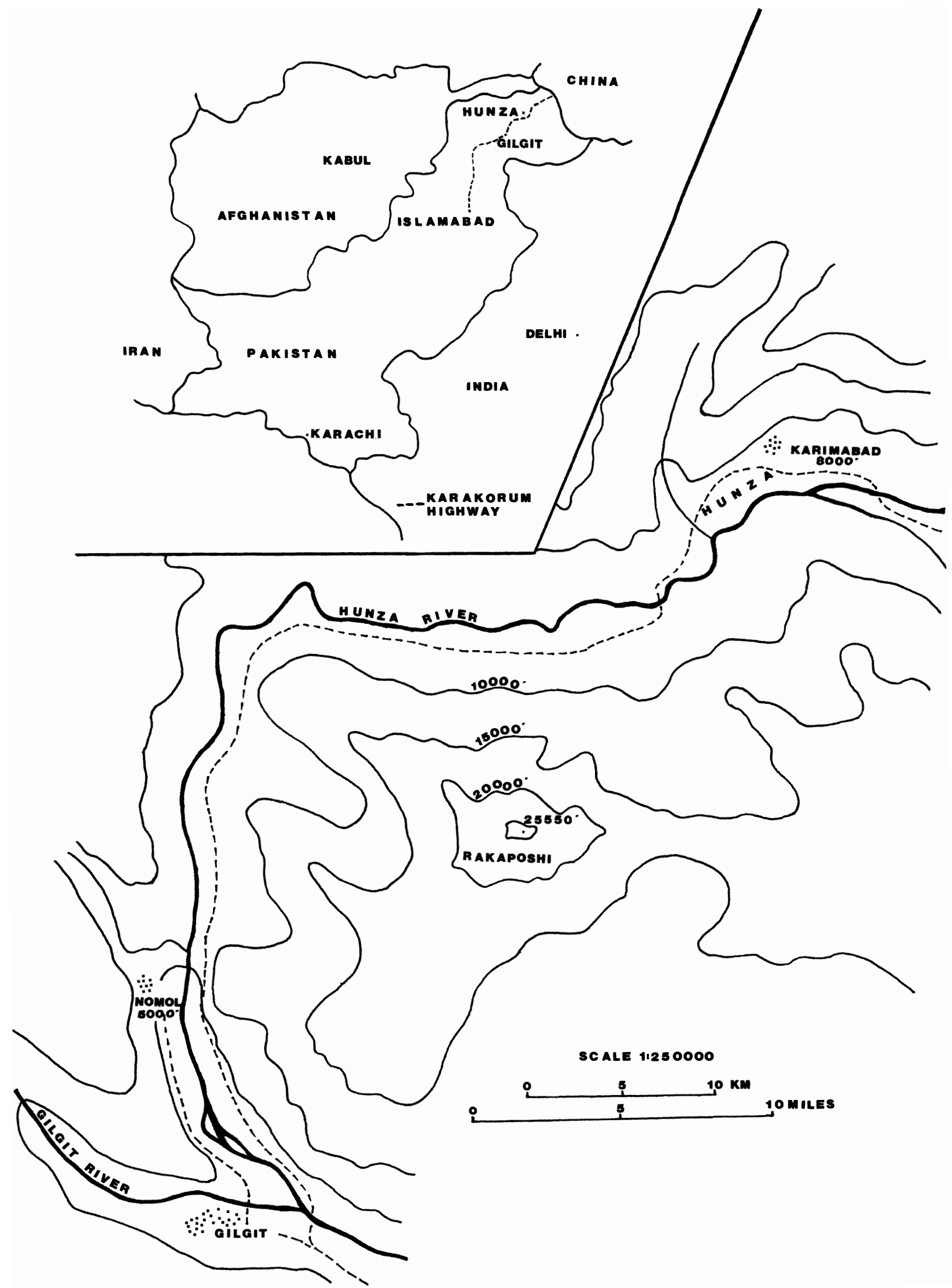

Fig. 4. A relief map of the Northern Areas of Pakistan where the expedition took place. 
Table IV. Age-specific cataract prevalence in outdoor and indoor workers (male) in Hunza and Nomol

\begin{tabular}{|c|c|c|c|c|c|c|c|c|c|c|}
\hline & \multicolumn{2}{|c|}{$40-49$ years } & \multicolumn{2}{|c|}{ 50-59 years } & \multicolumn{2}{|c|}{$60-69$ years } & \multicolumn{2}{|c|}{$70+$ years } & \multicolumn{2}{|c|}{ Total } \\
\hline & Hunza & Nomol & Hunza & Nomol & Hunza & Nomol & Hunza & Nomol & Hunza & Nomol \\
\hline \multicolumn{11}{|l|}{ Outdoor workers } \\
\hline$n$ & 28 & 25 & 30 & 40 & 38 & 44 & 40 & 35 & 136 & 144 \\
\hline No. with cataracts & 10 & 5 & 7 & 11 & 19 & 15 & 25 & 28 & 61 & 59 \\
\hline Prevalence $(\%)$ & 35.7 & 20.0 & 23.3 & 27.5 & 50.0 & 34.1 & 62.5 & 80.0 & 44.8 & 41.0 \\
\hline \multicolumn{11}{|l|}{ Indoor workers } \\
\hline$n$ & 23 & 31 & 25 & 19 & 14 & 10 & 6 & 2 & 68 & 62 \\
\hline No. with cataracts & 7 & 1 & 5 & 0 & 10 & 1 & 4 & 2 & 26 & 4 \\
\hline Prevalence (\%) & 30.4 & 3.2 & 20.0 & 0.0 & 71.4 & 10.0 & 66.7 & 100.0 & 38.2 & 6.5 \\
\hline
\end{tabular}

The major findings of this study are firstly an increasing cataract prevalence with age (a trend seen in previous studies), possibly reflecting the cumulative nature of damage to the lens. ${ }^{5,6}$ Secondly, there was no significant difference in cataract prevalence between the women of Hunza and Nomol; the male outdoor workers of Hunza and Nomol; and the male indoor and outdoor workers of Hunza. Finally, however, the cataract prevalence in men working predominantly indoors in Hunza (more UV light) was significantly higher than that of indoor workers in Nomol $(p<0.001)$.

Although the overall weight of this data is not supportive of the involvement of UV light in cataractogenesis, these apparently contradictory results may be explained in terms of a saturation effect of UV light on cataract prevalence. This possible relationship between UV light exposure and cataract prevalence may be explained in terms of a saturation point. Above this point, additional exposure may not significantly increase cataract prevalence. The outdoor workers in Hunza and Nomol may have experienced exposure at or above this hypothetical saturation point and thus show no significant difference in an already high cataract prevalence. However, the indoor workers in Nomol may have experienced exposure below this saturation point, resulting in their significantly lower prevalence of cataract when compared with the indoor workers in Hunza.

Such an interpretation may be criticised on the basis of other confounding factors. There is a significant difference in age distribution between indoor and outdoor workers in both villages, with the indoor workers being younger, and there is a slight difference in the mean age between the indoor workers of the two villages (Table III). There may be a socio-economic bias in favour of the indoor workers. Although the indoor and outdoor workers are not directly comparable, the cataract prevalence in these two groups remains consistent with a saturation model as there is still an age-specific difference in cataract prevalence between indoor workers in Nomol and outdoor workers in both valleys (Table IV).
There are a number of methodological problems with this study. Firstly, the observers who graded the lens opacities could not be masked from the main exposure status of the villages due to geographical constraints. Secondly, there was no formal population census data available, but we feel that we have circumvented this problem by visiting each household in both villages. Thirdly, the reported age from individuals was potentially inaccurate and there was also the potential for misinformation from visitors attempting to gain medical examination of their eyes. However, we attempted to verify age by relating the lives of the subjects to key life events (e.g. Pakistani partition). All visitors to the central unit were examined and treated by the Pakistani ophthalmologist with us, but subjects were only recruited if resident in the two study villages.

There may be an association between cortical ${ }^{9-11}$ and posterior subcapsular cataracts ${ }^{12}$ and UV light. Dolin, ${ }^{13}$ however, found no consistent relationship between UV light and cataract subtypes. Analysis of prevalence of cataract subtypes (cortical, posterior subcapsular and nuclear) was not possible in this study as the numbers involved were too small.

A problem with previous studies has been the confusion over the relationship between altitude and the increased UV light exposure. Brilliant et al. ${ }^{5}$ conducted a survey in Nepal which showed that cataract prevalence was negatively correlated with altitude. This was also shown by Chatterjee et al. ${ }^{6}$ in the Himalayas. In the light of this Harding ${ }^{14}$ and others have 'concluded that sunlight was not responsible for a significant proportion of the excess cataract in third world countries'. Other studies have found a positive correlation between cataract prevalence and altitude. ${ }^{15-17}$ Brilliant et al. ${ }^{5}$ also showed that exposure to UV light depended not only on altitude but also on the degree of obstruction of sunlight by the surrounding mountains. Taking this into consideration, they concluded that UV light is a factor in cataract formation. Other studies have confirmed this view, including the Chesapeake Bay study ${ }^{11}$ the Tibet Eye Study ${ }^{18}$ and the Beaver Dam Study. ${ }^{9}$ 
We would once again stress that altitude is not directly correlated with UV light exposure because the cornea absorbs all photons of wavelengths shorter than $300 \mathrm{~nm}$ that have not been absorbed by the atmosphere, which is optically thin to wavelengths greater than $310 \mathrm{~nm}$. The most important factors influencing UV light exposure to the lens in the range of $300-500 \mathrm{~nm}$ are in fact ground reflectivity and topography. ${ }^{7}$ The differing conclusions drawn from previous studies may be due to not having fully evaluated the role of reflectivity and topography and to an undue emphasis on the role of altitude. We would urge investigators in this field to take these factors into account in any future study.

We conclude that UV light exposure is a possible risk factor for cataract formation and we have suggested that there may be a saturation effect, whereby above a certain cut-off point further exposure to UV light would not significantly increase the prevalence of cataract.

We thank Professor G. Johnson, Dr D. Minassian, Professor D. Khan, Dr Sadiqullah Khan, Professor K. Khaw and Mr P. G. Watson for their advice and support.

Key words: Cataract, Pakistan, Ultraviolet radiation.

\section{REFERENCES}

1. Kupfer C. Bowman lecture. The conquest of cataract: a global challenge. Trans Ophthalmol Soc UK 1984; 104:1-10.

2. Cheng H. Causes of cataract (editorial). BMJ 1989; 298:1470-1.

3. Chatterjee A. Cataract in Punjab. In: Elliot K, Fitzsimons DW, editors. Symposium on the human lens in relation to cataract. Ciba foundation symposium 19. Amsterdam: Associated Scientific Publishers, 1973: 265-79.

4. Minassian DC, Mehra V, Verry J-D. Dehydrational crises: a major risk factor in the blinding cataract. Lancet 1989;73:100-5.
5. Brilliant L, Grasset N, Pokhrel R, Kolstad A, Lepkowski J, Brilliant $\mathrm{G}$, et al. Associations among cataract prevalence, sunlight hours, and altitude in the Himalayas. Am J Epidemiol 1983;118:250-64.

6. Chatterjee A, Milton RC, Thyle S. Prevalence and aetiology of cataract in the Punjab. Br J Ophthalmol 1982;66:35-42.

7. Sliney DH. Physical factors in cataractogenesis: ambient ultraviolet radiation and temperature. Invest Ophthalmol Vis Sci 1986;27:781-90.

8. Mehra V, Minassian DC. A rapid method of grading cataract in epidemiological studies and eye surveys. $\mathrm{Br}$ J Ophthalmol 1988;72:801-3.

9. Cruickshanks KJ, Klein BE, Klein R. Ultraviolet light exposure and lens opacities: the Beaver Dam Eye Study. Am J Public Health 1992;82:1658-62.

10. Hiller $\mathrm{R}$, et al. Epidemiological associations with nuclear, cortical and posterior subcapsular cataracts. Am J Epidemiol 1986;124:917-25.

11. Taylor HR, et al. Effect of UV radiation on cataract formation. N Engl J Med 1988;319:1429-33.

12. Bochow TW, et al. UV light exposure and risk of posterior sub-capsular cataracts. Arch Ophthalmol 1989; 107:369-72.

13. Dolin PJ. Ultra-violet radiation and cataract: a review of the epidemiological evidence. $\mathrm{Br} \mathrm{J}$ Ophthalmol 1994;78:478-82.

14. Harding JJ. Cataract: biochemistry, epidemiology and pharmacology. London: Chapman and Hall, 1991: 106-14.

15. Goldsmith R, Rothhammer F, Schull W. The multinational Andean genetic and health programme. III. Ophthalmic disease and disability among the Aymara. Bull Pan Am Health Organ 1980;13:58-65.

16. Vines AP. An epidemiological sample survey of the highlands, mainland and island regions of the territory of Papua and New Guinea. Port Moresby, New Guinea: Government Printer, 1967.

17. Seung Wen-shi. A survey of senile cataract among high altitude living Tibetans in Changdu district, Tibet. Chinese J Ophthalmol 1979;15:100-4.

18. Hu TS, et al. Age-related cataract in the Tibet Eye Study. Arch Ophthalmol 1989;107:666-9. 